\section{BRAZIULIAN JOURNAL \\ OF MEDICAL AND BIOLOGICAL RESHARCH}

www.bjournal.com.br
ISSN 0100-879X

Volume 42 (11) 993-1118 November 2009

BIOMEDICAL SCIENCES

AND

CLINICAL INVESTIGATION

Braz J Med Biol Res, November 2009, Volume 42(11)1050-1057

Purine nucleotides reduce superoxide production by nitric oxide synthase in a murine sepsis model

H.V. Barbeiro, D.F. Barbeiro, V. Debbas, H.P. Souza, F.R. Laurindo, I.T. Velasco and

F.G. Soriano

The Brazilian Journal of Medical and Biological Research is partially financed by
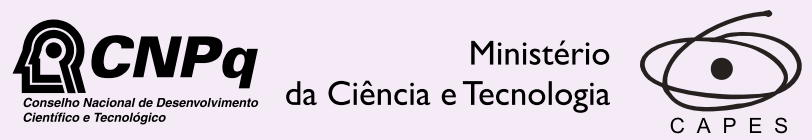

Ministério da Educação

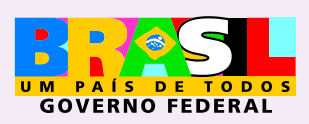

Institutional Sponsors 


\title{
Purine nucleotides reduce superoxide production by nitric oxide synthase in a murine sepsis model
}

\author{
H.V. Barbeiro, D.F. Barbeiro, V. Debbas, H.P. Souza, \\ F.R. Laurindo, I.T. Velasco and F.G. Soriano \\ Emergências Clínicas, Departamento de Clínica Médica (LIM51), Faculdade de Medicina, \\ Universidade de São Paulo, São Paulo, SP, Brasil
}

\begin{abstract}
Sepsis involves a systemic inflammatory response of multiple endogenous mediators, resulting in many of the injurious and sometimes fatal physiological symptoms of the disease. This systemic activation leads to a compromised vascular response and endothelial dysfunction. Purine nucleotides interact with purinoceptors and initiate a variety of physiological processes that play an important role in maintaining cardiovascular function. The purpose of the present study was to investigate the effects of ATP on vascular function in a lipopolysaccharide (LPS) model of sepsis. LPS induced a significant increase in aortic superoxide production $16 \mathrm{~h}$ after injection. Addition of ATP to the organ bath incubation solution reduced superoxide production by the aortas of endotoxemic animals. Reactive Blue, an antagonist of the P2Y receptor, blocked the effect of ATP on superoxide production, and the nonselective P2Y agonist MeSATP inhibited superoxide production. Nitric oxide synthase (NOS) inhibition by L-NAME blocked vascular relaxation and reduced superoxide production in LPS-treated animals. In the presence of L-NAME there was no ATP effect on superoxide production. A vascular reactivity study showed that ATP increased maximal relaxation in LPS-treated animals compared to controls. The presence of ATP induced increases in Akt and endothelial NOS phosphorylated proteins in the aorta of septic animals. ATP reduces superoxide release resulting in an improved vasorelaxant response. Sepsis may uncouple NOS to produce superoxide. We showed that ATP through Akt pathway phosphorylated endothelial NOS and "re-couples" NOS function.
\end{abstract}

Key words: ATP; Endotoxin; Endothelium; Superoxide; Nitric oxide

\section{Introduction}

Sepsis is one of the main causes of death in noncoronary intensive care units and, despite advances in the understanding of its pathophysiology, epidemiology, and treatment, the mortality rate remains high (1). A systemic inflammatory response involving multiple endogenous mediators is deflagrated, causing tissues and organ damage (2). The systemic release of free radicals leads to a compromised vascular response and endothelial dysfunction (3).

Vascular dysfunction characterized by compromised vasoconstriction and vasodilatation functions aggravates organ perfusion, leading to a vicious cycle of more tissue damage. Endothelial dysfunction in vascular disease states is associated with reduced nitric oxide (NO) bioactivity. Endothelial NO synthase (eNOS) uncoupling, whereby eNOS generates $\mathrm{O}_{2}{ }^{-}$- rather than $\mathrm{NO}$, is a mechanism underlying endothelial dysfunction (4). Brandes et al. (5) reported increased production of superoxide and hydrogen peroxide by vascular rings of rats treated with lipopolysaccharide (LPS), mainly by endothelial cells. Javesghani et al. (6) recently reported in addition an increase in peroxynitrite generation after LPS injection. These data suggest that some of the toxic effects of superoxide in sepsis may actually be caused by peroxynitrite (7). In addition, sepsis induces endothelial activation (8) with release of ATP and ADP from platelets and vasculature (9). ATP and ADP are released by cell lysis, selective permeabilization of the plasma membrane and secretion from platelet dense bodies in response to specific mediators (10-13). Purine nucleotides have the

Correspondence: F.G. Soriano, Emergências Clínicas, Departamento de Clínica Médica (LIM51), FM-USP,

Av. Dr. Arnaldo 455, Sala 3134, 01246-903 São Paulo, SP, Brasil. Fax: +55-11-3066-7170. E-mail: gsoriano@usp.br

Research supported by FAPESP.

Received March 26, 2009. Accepted August 26, 2009. Available online October 5, 2009. 
potential to modulate endothelial cells, platelet activation, leukocyte migration, and cytokine release (14). NO has been reported to regulate the mitochondrial respiratory cascade and to increase superoxide production with a lower production of ATP, an important event in sepsis $(15,16)$. At the same time, oxidative stress activates poly(ADP-ribose) polymerase that consumes ATP (17). ATP has been reported to modulate the vascular release of $\mathrm{NO}$ under physiological conditions (18) and to modulate the release of superoxide in macrophages $(19,20)$ as well as inflammatory mediators by the autonomic system (21).

The effect of ATP on vascular and endothelial function in sepsis has not been studied. We present data showing that ATP increased vascular relaxation in septic rings, an important fact from a clinical viewpoint. Therefore, we hypothesized that ATP is able to repair endothelial dysfunction. In order to attempt to understand this process, we determined the actions of ATP on vascular function during sepsis in terms of vascular reactivity and their correlation with superoxide and NO production and eNOS phosphorylation.

\section{Material and Methods}

The Ethics Committee for Analysis of Research Projects (CAPPesq) approved the present in vivo study, which was conducted according to CAPPesq guidelines and according to the Guide for the Care and Use of Laboratory Animals adopted and promulgated by the U.S. National Institutes of Health.

\section{Experimental protocol}

Forty male Wistar rats weighing 240-260 g were randomly assigned to 2 groups: one group received $10 \mathrm{mg} / \mathrm{kg}$, ip, LPS (Escherichia coli serotype 026:B6) and the other received saline ip. Animals were sacrificed $16 \mathrm{~h}$ after LPS or vehicle injection.

\section{Aorta preparation}

The aorta preparation was the same for the experiments of vascular superoxide generation and vascular reactivity. The thoracic aortas were harvested, cleared of periadvential fat and were handled carefully to preserve an intact endothelium. The aortic rings (4-5 $\mathrm{mm})$ were kept in warmed $\left(37^{\circ} \mathrm{C}\right)$ and gas-equilibrated $\left(95 \% \mathrm{O}_{2}, 5 \% \mathrm{CO}_{2}\right)$ Krebs solution containing: $1.6 \mathrm{mM} \mathrm{CaCl}_{2}, 1.17 \mathrm{~mm} \mathrm{MgSO}_{4}$, $26 \mu \mathrm{M}$ EDTA, $130 \mathrm{mM} \mathrm{NaCl}, 14.9 \mathrm{mM} \mathrm{NaHCO} 3,4.7 \mathrm{mM}$ $\mathrm{KCl}, 1.18 \mathrm{mM} \mathrm{KH}_{2} \mathrm{PO}_{4}$, and $11 \mathrm{mM}$ glucose.

\section{Vascular superoxide production \\ Lucigenin-amplified chemiluminescence assays. Each rat aorta segment was immersed in Krebs buffer at $\mathrm{pH}$ 7.40 , for $20 \mathrm{~min}$. The arterial segments were then rapidly transferred to a counting vial under light protection and im- mersed in a $5-\mu \mathrm{M}$ lucigenin (Sigma, USA) solution in Krebs}

buffer (total volume $=1.0 \mathrm{~mL}$ ). This lucigenin concentration is within the range proposed to be less likely to undergo redox cycling, reflecting, therefore, superoxide generation by tissues $(5,6)$. The luminescence emitted by each fragment was measured for 5 min in a Berthold Multi Biolumat luminometer (Berthold, Germany). Background signals from buffer and lucigenin were subtracted from artery signals and the resulting value was normalized for dry weight. Data are reported as counts per min (cpm) per mg of dry tissue. Chemiluminescence was measured directly and continuously for $5 \mathrm{~min}$ to obtain basal values. Superoxide generation from rat aortic ring segments was obtained under several experimental conditions. To analyze the role of specific pathways, some compounds were added at the following final concentrations: 1) $1 \mathrm{mM} \mathrm{L-NAME,} \mathrm{2)} 10 \mu \mathrm{M}$ reactive blue, 3) $1 \mu \mathrm{M}$ pyridoxalphosphate-6-azophenyl2',4'-disulfonic acid (PPADS), 4) 0.1 mM 2-methylthioadenosine 5'-triphosphate (2MeSATP; a non-selective P2Y agonist), and 5) $30 \mu \mathrm{M} \beta-\gamma$-methylene-ATP (a partially selective $P 2 X$ antagonist). After $5 \mathrm{~min}$ a new record of superoxide production was obtained. ATP was added at a final concentration of $0.1 \mathrm{mM}, 10 \mathrm{~min}$ after addition of the compounds, and after $5 \mathrm{~min}$ a new record of superoxide production was obtained.

\section{Vascular reactivity in isolated aortic rings}

The thoracic aortas were mounted in organ baths filled with warm $\left(37^{\circ} \mathrm{C}\right)$ and gas-equilibrated Krebs solution. Isometric tension was measured with isometric transducers (Biopac Systems, TSD105A, USA), digitized, stored, and displayed on a computer. The pre-load was $1.5 \mathrm{~g}$ and the solution was changed every $20 \mathrm{~min}$ within the first hour (22). A dose-response curve for ATP (10 nM to 100 $\mu \mathrm{M})$ was constructed after preconstriction with $0.1 \mu \mathrm{M}$ norepinephrine. L-NAME was added to the bath solution to a final concentration of $1 \mathrm{mM}$ and the aortic rings were pre-incubated for 15 min before the determination of the dose-response curve for ATP.

\section{Nitrate content in the aorta}

Harvested aortas were snap frozen in liquid nitrogen and then homogenized with a stainless steel mortar cooled in liquid nitrogen. Tissue dry powder was dissolved in Krebs solution and centrifuged at $1600 \mathrm{~g}$ for $5 \mathrm{~min}$. The supernatant was then injected into the NO analyzer (Sievers Instrument, USA) for direct assessment of NO and metabolites. Nitrate content was normalized according to protein concentration in the extract and the amount of protein in tissue homogenates was assayed by the method of Bradford.

\section{iNOS identification and quantification in aorta}

RNA was extracted from aorta tissue with Trizol ${ }^{\circledR}$ (Gibco$B R L$, USA) according to manufacturer instructions. RT-PCR was performed using ImProm-II Reverse Transcriptase (Promega, USA) with $1 \mathrm{\mu g}$ of total RNA as a template 
annealed with Oligo dT (Promega) for cDNA synthesis. This reaction was performed at $42^{\circ} \mathrm{C}$ for 50 min followed by $70^{\circ} \mathrm{C}$ for $15 \mathrm{~min}$ to inactivate the reverse transcriptase enzyme. For inducible NOS (iNOS) amplification, PCR was performed with 35 cycles of $94^{\circ} \mathrm{C}$ for $30 \mathrm{~s}, 92^{\circ} \mathrm{C}$ for $1 \mathrm{~min}$, $63.5^{\circ} \mathrm{C}$ for $1 \mathrm{~min}$, and $72^{\circ} \mathrm{C}$ for $1 \mathrm{~min}$ followed by a final extension for $10 \mathrm{~min}$ at $72^{\circ} \mathrm{C}$. The following primers were used to amplify $170 \mathrm{bp}$ for rat iNOS (Gen Bank accession No. D44591) forward primer: 5' CAC CTT GGA GTT CAC CCA GT 3' and reverse primer: 5' ACC ACT CGT ACT TGG GAT GC 3'. GAPDH was used as a housekeeping gene. The reactions were carried out in an MJ Research Thermal Cycler PTC 200 (USA). The products were electrophoresed on $1 \%$ agarose gel and visualized by ethidium bromide staining. Densitometry values were normalized to GAPDH expression using the ImageJ program and the quantity of mRNA was determined with the Genius Plus software (TECAN Austria GMBH, Austria).

\section{Identification of the phosphorylated proteins: Akt and eNOS}

Pulverized vessels were rehydrated with lysis buffer containing $20 \mathrm{mM}$ HEPES, $150 \mathrm{mM} \mathrm{NaCl}, 1.5 \mathrm{mM} \mathrm{MgCl}_{2}$, $1.0 \mathrm{mM}$ EGTA, 10\% glycerol, $1 \%$ Triton, $1 \mu \mathrm{g} / \mathrm{mL}$ aprotinin, $1 \mu \mathrm{g} / \mathrm{mL}$ leupeptin, $1.0 \mathrm{mM}$ PMSF and phosphatases inhibitors (2 mM sodium orthovanadate, $50 \mathrm{mM}$ sodium fluoride, and $10 \mathrm{mM}$ sodium pyrophosphate). Total protein concentration was determined with the Bio-Rad Protein Assay (Bio-Rad, USA). After heating at $100^{\circ} \mathrm{C}$ for $5 \mathrm{~min}, 50 \mathrm{\mu g}$ protein under reduced conditions (phospho-Akt and $\beta$-actin antibodies) and under non-reduced conditions (eNOS and phospho-eNOS antibodies) were resolved by SDS-PAGE on a $10 \%$ gel and transferred to a nitrocellulose membrane. The nitrocellulose membranes were incubated in blocking buffer (TBS with 5\% milk and $0.05 \%$ Tween 20) for $2 \mathrm{~h}$ at room temperature and then probed with mouse anti-eNOS (1:1000, Calbiochem, USA), mouse anti-phospho-eNOS (1:1000, Calbiochem), rabbit anti-phospho-Akt antibody (1:500, Santa Cruz Biotech, USA), and mouse anti- $\beta$-actin $\left(1: 10,000\right.$, Sigma-Aldrich, USA) overnight at $4^{\circ} \mathrm{C}$. The membranes were then washed and incubated with horseradish peroxidase-conjugated goat anti-mouse $\lg$ (1:2000 for eNOS, 1:2000 for phospho-eNOS, and 1:10,000 for $\beta$-actin; Calbiochem) or horseradish peroxidase-conjugated goat anti-rabbit IgG (1:1500 for phospho-Akt; Calbiochem). Proteins were visualized using the ECL Western Blotting Analysis System (GE Healthcare, USA).

\section{Reagents}

All chemicals were purchased from Sigma, except when otherwise stated.

\section{Statistical analyses}

Data are reported as means \pm SEM in all figures. The Student $t$-test was used to compare two groups and
ANOVA was used for three or more groups, followed by the Bonferroni post-test. The level of significance was set at $\mathrm{P}<0.05$.

\section{Results}

\section{Endotoxemic aortic rings presented increased relaxation in response to ATP}

Endothelium-dependent relaxation (acetylcholine) is impaired in endotoxemic animals (23). We first determined whether aortic rings from LPS animals presented different relaxant responsiveness to ATP compared to control. There was a greater relaxation response to ATP in LPS animals vs control (106.72 \pm 2.29 vs $100.15 \pm 0.85 \%$; $\mathrm{P}<$ 0.05; Figure 1).

\section{ATP vasorelaxation is mediated by NOS}

We used L-NAME (1 $\mathrm{mM})$ in vitro during vascular reactivity procedures to determine the role of vascular NO production by ATP $(10 \mathrm{nM}$ to $100 \mu \mathrm{M})$. L-NAME inhibits NOS and is a useful tool employed to analyze if vasorelaxation is NO related. L-NAME almost completely blocked the relaxation response to ATP (Figure 2A,B) in the aortas from both control and LPS-treated animals.

\section{ATP decreases NOS superoxide production in sepsis}

There was a significant increase of superoxide in aorta from LPS animals vs control (9424.6 \pm 1098.9 vs $1212 \pm$ 127.3 counts/mg aorta). ATP reduced superoxide release to $4769.7 \pm 797.9$ counts/mg dry aorta tissue in LPS-treated animals $(P<0.05$; Figure 3$)$.

NOS-dependent superoxide production was analyzed using the NOS inhibitor L-NAME, which reduced superoxide

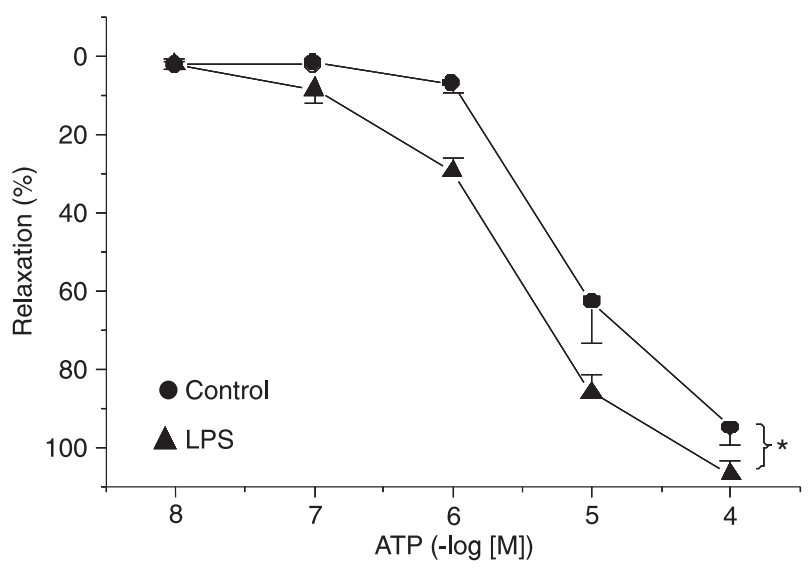

Figure 1. Rat vascular ring reactivity. Thoracic aortas were harvested $16 \mathrm{~h}$ after lipopolysaccharide (LPS) or saline administration and their relaxation in response to ATP was measured. Data are reported as means \pm SEM for each experimental group containing 6 rats. A significant increase in maximal relaxation in response to ATP occurred in LPS-treated animals compared to control ( ${ }^{*} P<0.05$, Student $t$-test). 
production by LPS aortic rings: $13,277 \pm 695$ counts/mg aorta for LPS vs $6614 \pm 640$ counts/mg aorta for LPS-LNAME $(P<0.05$; Figure 4). The superoxide release-reducing effect of ATP was completely blocked by L-NAME: $6614 \pm$ 640 counts/mg aorta for LPS-L-NAME vs $6753 \pm 525$ counts/ mg aorta for LPS-L-NAME-ATP ( $P>0.05$; Figure 4).

A direct measurement of nitrate and iNOS in aortic rings was also conducted. The aortic rings taken from LPS animals showed a significantly higher peak of nitrate content (17.4 \pm 3.5 vs $5.25 \pm 0.4 \mu \mathrm{M} / \mathrm{mg}$ protein for LPS vs control; $\mathrm{P}<$ 0.05 ; Figure $5 \mathrm{~A}$ ). iNOS expression analyzed by RT-PCR was also increased in LPS animals (Figure 5B).

\section{The effect of ATP is mediated via P2Y}

$\mathrm{P} 2 \mathrm{X}$ and $\mathrm{P} 2 \mathrm{Y}$ inhibitors were added to the bath solution and only the reactive blue P2Y inhibitor blocked the effect of ATP in reducing superoxide production (4129 \pm 601 vs $3797 \pm$ 946; $P>0.05$; Figure 6), while the P2X inhibitor PPADS did not block the action of ATP $(6078 \pm 822$ vs $3361 \pm 438$; $P<0.05$; Figure 6). Different agonists were used to check and confirm the purinergic receptor. When 2MeSATP (a non-selective P2Y agonist) and $\beta$ - $\gamma$-methylene ATP (partially selective P2X) were
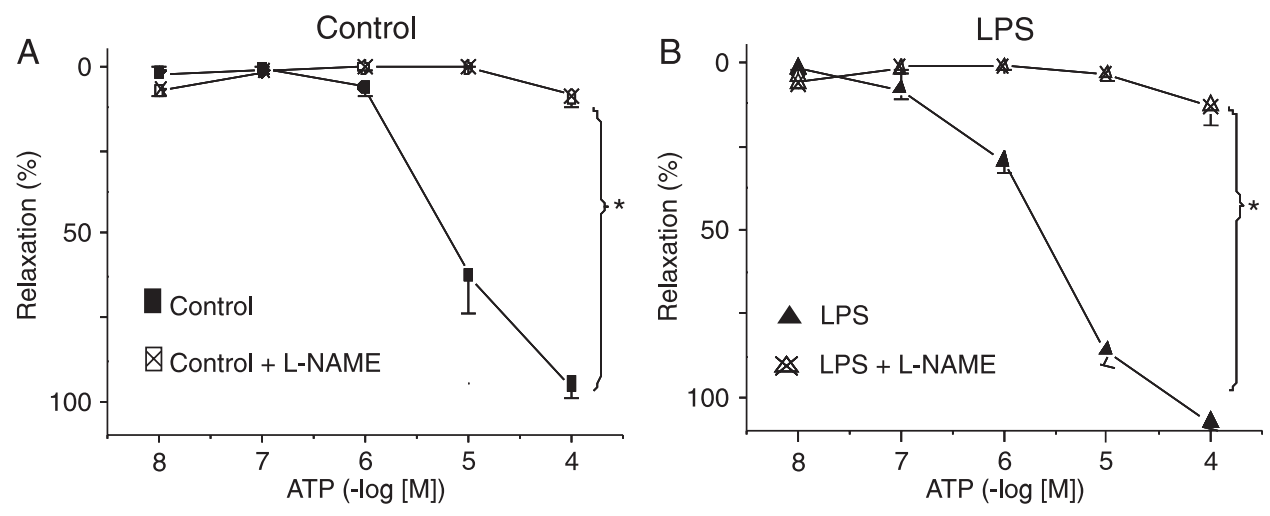

Figure 2. The role of nitric oxide in ATP relaxation of vascular rings. Thoracic aortas were harvested $16 \mathrm{~h}$ after saline (A) or lipopolysaccharide (LPS; B) administration to measure relaxation in response to ATP with or without L-NAME (1 mM). Data are reported as means \pm SEM for each experimental group containing 6 rats. A significant decrease of relaxation occurred with L-NAME $\left({ }^{*} P<0.05\right.$, Student $t$-test).

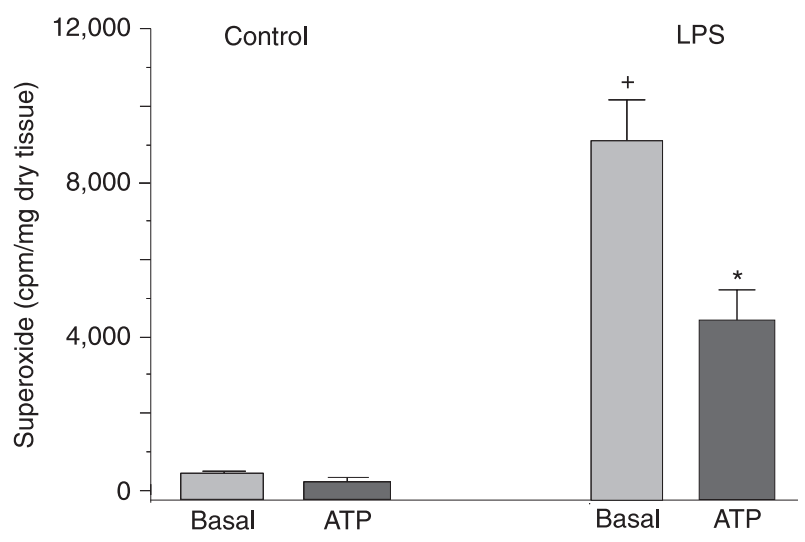

Figure 3. Effect of lipopolysaccharide (LPS) and ATP on superoxide production by aortic rings incubated ex vivo. Thoracic aortic rings were harvested from control rats or from experimental rats $16 \mathrm{~h}$ after LPS administration to measure superoxide production. ATP was added to the bath solution during incubation in order to obtain a $5-\mu \mathrm{M}$ final concentration. Data are reported as means \pm SEM for each experimental group containing 9 rats. ${ }^{+} P<0.05$ for basal control vs basal LPS: a significant increase of superoxide production occurred compared to control animals; ${ }^{*} P<0.05$ for basal LPS vs LPS plus ATP: a significant direct action of ATP reducing superoxide production in LPS-treated animals compared to baseline (ANOVA and Bonferroni's test).

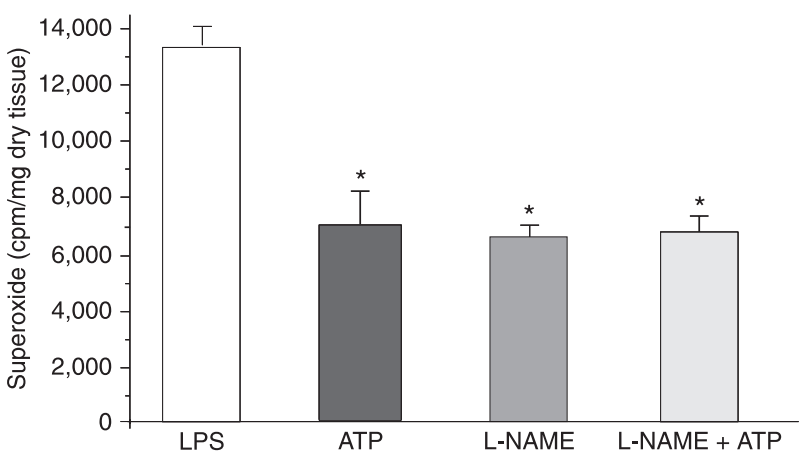

Figure 4. Effect of L-NAME on superoxide production by aorta incubated ex vivo. Thoracic aortic rings were harvested from rats $16 \mathrm{~h}$ after lipopolysaccharide (LPS) administration to measure superoxide production. Superoxide production was measured in the same aortic ring sequentially under three conditions: 1) basal; 2) L-NAME addition (1 $\mathrm{mM})$; 3) followed by ATP addition $(0.1 \mathrm{mM})$. Data are reported as means \pm SEM for each experimental group containing 9 rats. ${ }^{*} P<0.05$, significant decrease of superoxide production compared to basal LPS (ANOVA and Bonferroni's test). There was no decrease in superoxide production when LPS L-NAME was compared to LPS L-NAME plus ATP. 
incubated with aortic rings, only $2 \mathrm{MeSATP}$ reduced superoxide production $(5537 \pm 821$ vs $4905 \pm 946$; $\mathrm{P}<0.05)$, whereas $\beta$ - $\gamma$-methylene ATP did not modify superoxide production (5402 \pm 911 vs $5491 \pm 735$; Figure 6).

\section{ATP increases aortic content of the phosphorylated proteins: Akt (p-Akt) and eNOS (p-eNOS)}

The addition of ATP to the bath solution containing the aortic rings produced a transient increase in p-Akt (Figure 7A,B)
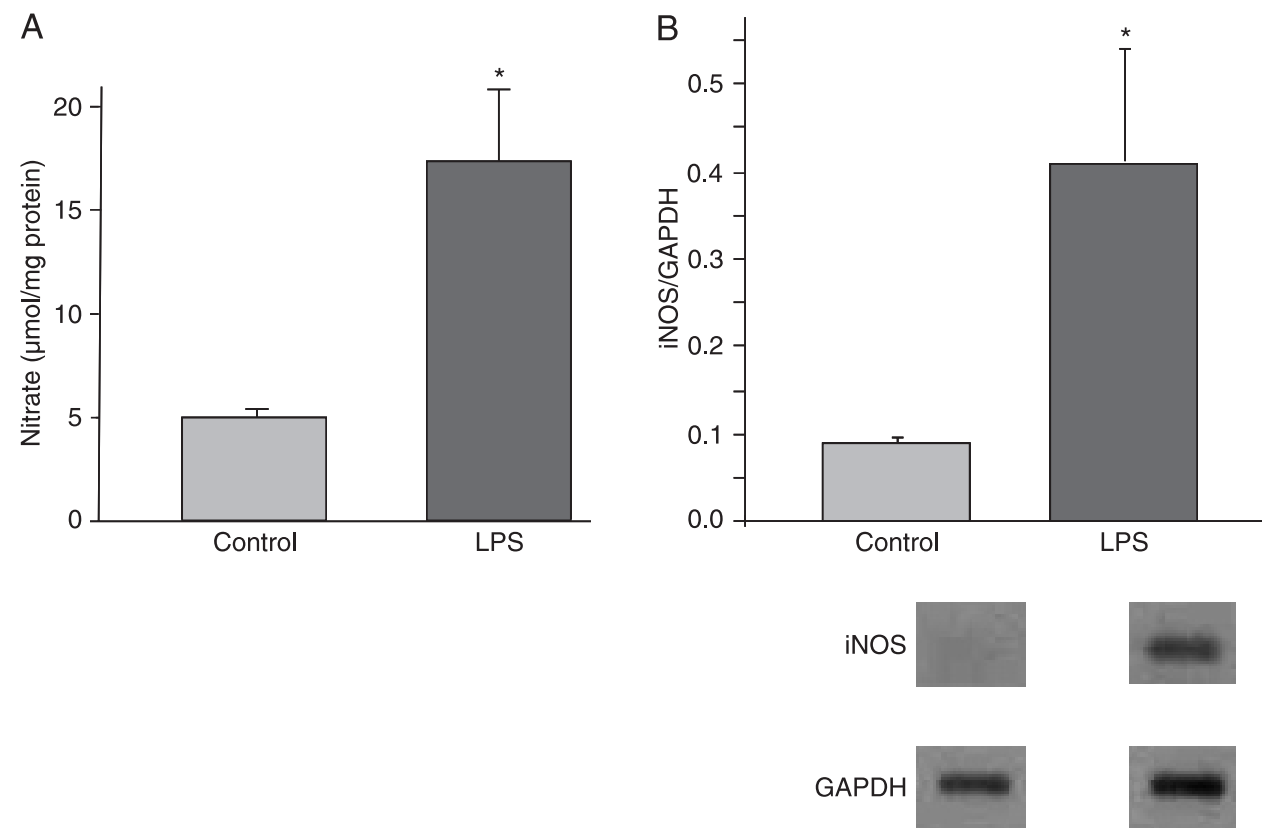

Figure 5. Nitric oxide production after lipopolysaccharide (LPS) administration. $A$, Nitrate concentration in aortic rings. There was a significant increase of nitrate content in the aorta after LPS administration. B, RT-PCR for inducible nitric oxide synthase (iNOS) expression in aortic rings. Data are reported as means \pm SEM for each experimental group containing 6 rats. GAPDH $=$ glyceraldehyde3-phosphate dehydrogenase. There was an increased expression of iNOS after LPS injection compared with control animals. ${ }^{*}<<0.05$ for control vs LPS (Student $t$-test).
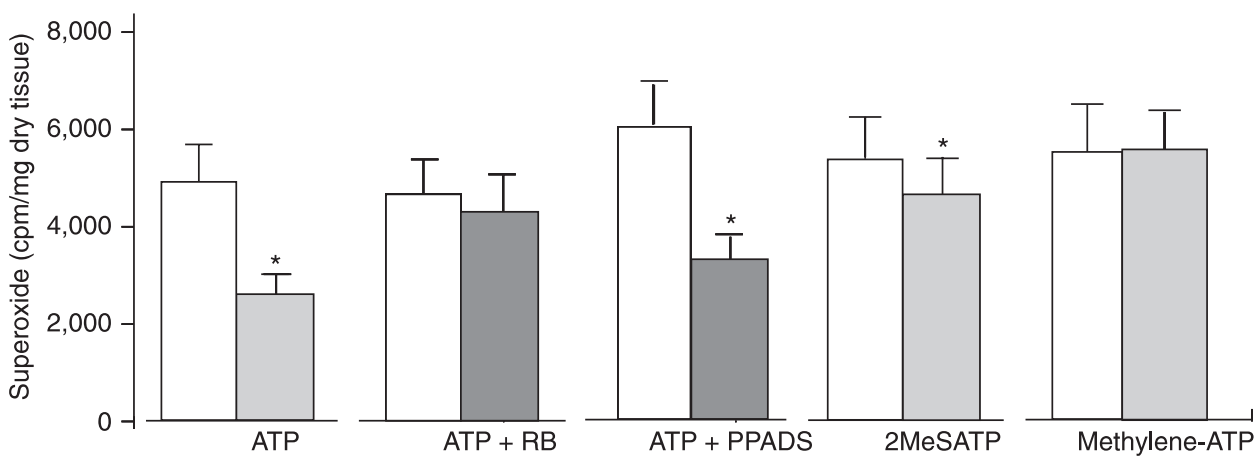

Figure 6. Effect of ATP, ATP agonists and inhibitors on superoxide production by aorta incubated ex vivo. Thoracic aortic rings were harvested from rats $16 \mathrm{~h}$ after LPS administration to measure superoxide production. The aorta was initially incubated without any compound to obtain a basal value (white columns). After $10 \mathrm{~min}$, one of the following compounds was added: ATP (1 mM), 2MeSATP (0.1 mM - a nonselective agonist) or methylene-ATP $(30 \mu \mathrm{M}$ - a partially selective P2X). The inhibitors PPADS $(1 \mu \mathrm{M})$ or RB $(10 \mu \mathrm{M})$ were added to two sets of aortic rings to which ATP had been previously added. RB = reactive blue; PPADS = pyridoxalphosphate-6azophenyl-2',4'-disulfonic acid; 2MeSATP = 2-methylthioadenosine 5'-triphosphate. Data are reported as means \pm SEM for experimental group containing 9 rats. ${ }^{*} \mathrm{P}<0.05$, significant decrease of superoxide production compared to basal LPS (Student $t$-test). 

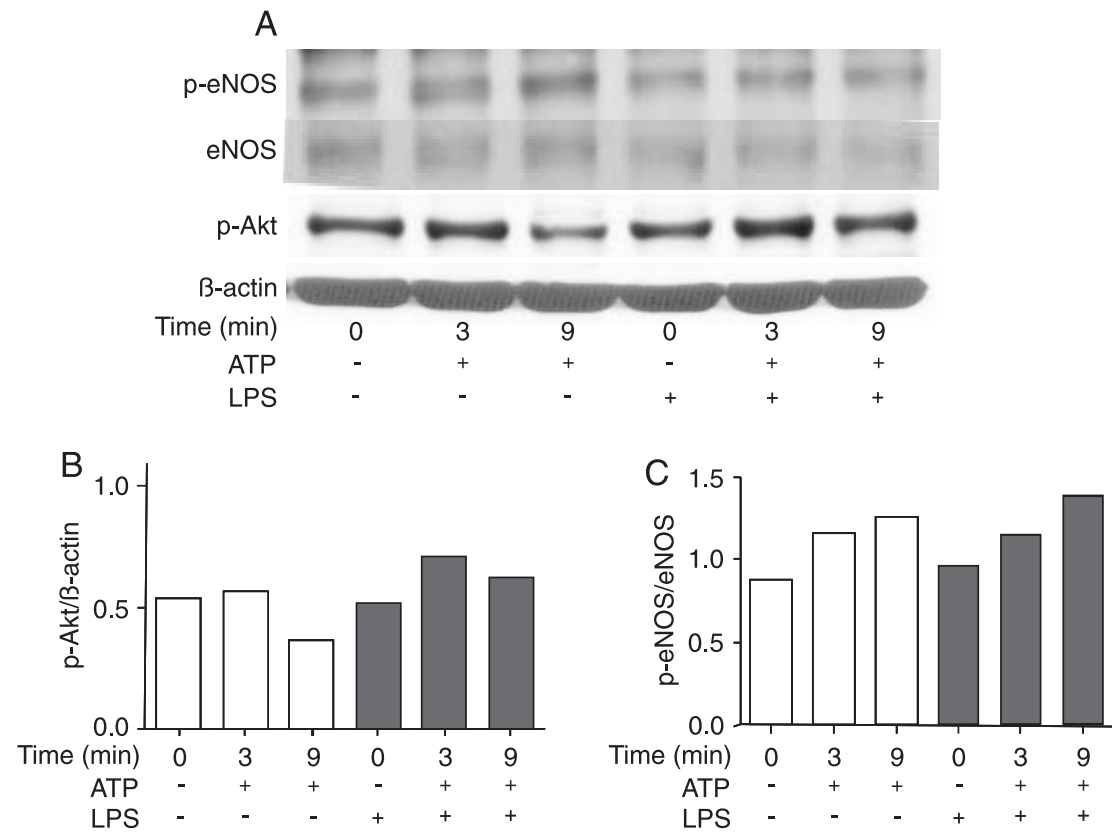

Figure 7. Phosphorylated proteins in a pool of 3 aortae after ATP incubation. $A$, Western blots of endothelial nitric oxide synthase (eNOS), $\beta$-actin and phosphorylated proteins ( $p$-eNOS and p-Akt). The images are from control, control plus ATP incubation (3 and 9 $\mathrm{min}$ ), septic aorta, and septic aorta plus ATP incubation ( 3 and $9 \mathrm{~min}$ ). $B$, p-Akt quantification of the Western blot data. The presence of ATP in the bath produced a transient increase in p-Akt of the septic aorta. $C$, p-eNOS to eNOS ratio of the Western blot data. The addition of ATP induced an increase of p-eNOS in the aorta of all animals. LPS = lipopolysaccharide. All assays were performed with 3 pooled aortae.

lasting $3 \mathrm{~min}$ and returning to basal levels thereafter. The increase in p-Akt was more intense in the LPS aorta group than in the control (Figure 7B). The presence of ATP induced an increase in the amount of $p$-eNOS in both the control and LPS groups (Figure 7A,C). The amount of total eNOS was lower in the LPS group than in the control group (Figure 7C).

\section{Discussion}

Sepsis is a well-known condition presenting an endothelium-dependent reduced vasorelaxation. Ex vivo experiments have demonstrated the loss of endothelial function in LPS-treated animals, as measured by the relaxant responsiveness of pre-contracted vascular rings to the endothelium-dependent vasodilator NO liberating the hormone acetylcholine. ATP is also known to induce NO synthesis and release; however, there are no studies of the vascular relaxant responsiveness to ATP of septic animals (10-13). The average concentration of nucleotides in plasma and in other extracellular fluids is generally in the 0.4- to $6-\mu \mathrm{M}$ range (24), and these values can increase at sites of vascular inflammation, ischemia and platelet degranulation (25). Our data confirm that ATP produces vasorelaxation through NO release. Figure 2 shows that L-NAME inhibited aorta relaxation induced by ATP in both control and LPS animals. ATP induced greater relaxation compared to control a result that is opposite to the effect of acetylcholine (23) detected in endotoxemic animals. The effect of ATP in increasing vascular caliber improves the matching between oxygen supply and metabolic demand (26).

In the present stud, the increased superoxide production in the aorta was followed by increased aortic nitrate content, iNOS mRNA expression, and increased amounts of nitrotyrosine in the aorta (data not shown). In various disease conditions, all types of NOS (neuronal, inducible, and endothelial) have been reported to generate oxidants through unknown mechanisms $(27,28)$. The catalytic activity of eNOS is exquisitely sensitive to $\mathrm{ONOO}^{-}$, which decreases $\mathrm{NO}$ synthesis and increases superoxide anion $\left(\mathrm{O}_{2}{ }^{\circ-}\right)$ production by the enzyme (29). Hence, eNOS exposure to oxidants including $\mathrm{ONOO}^{-}$causes increased enzymatic uncoupling and generation of $\mathrm{O}_{2}{ }^{\bullet-}$, further contributing to oxidant stress in endothelial cells (29). In the LPS group, ATP not only increased vasorelaxation (Figure 1) but significantly decreased superoxide production (Figure 3). The reduction in superoxide production by ATP may explain the better vasorelaxation performance of septic aortic rings. 
In addition, we showed that L-NAME also reduced superoxide production, in agreement with literature reports that superoxide production by uncoupled NOS was blocked by L-NAME but not by apocynin (an NADPH oxidase inhibitor) $(4,30)$. Next we checked the effect of ATP in the presence of L-NAME and we observed that the inhibitory effect of ATP on superoxide production was blocked by L-NAME. These data suggest that NOS activity was an important source of superoxide in the present study. In addition, the data suggest that the purinergic effect on superoxide production is related to the regulation of NOS activity. Therefore, the presence of ATP seems to reverse superoxide production by NOS and the NO release induced in septic aortas. Assays using different antagonists and agonists have confirmed that this effect is produced by purinergic activation. The action of ATP on superoxide production is due to the P2Y receptor, as confirmed by the experiments using agonists and antagonists the $\mathrm{P} 2 \mathrm{Y}$ and $\mathrm{P} 2 \mathrm{X}$ receptors. The $\mathrm{P} 2 \mathrm{Y}$ receptors in endothelial cells (P2Y1, P2Y2, and P2Y11) are $G$ protein-linked and activate the phosphoinositol system, leading to store-operated calcium influx after inositol $(1,4,5)$ P3-induced release of calcium from intracellular stores and, in the case of P2Y11, are also linked to the cAMP/protein kinase A pathway.

We found a maximal increase in $\mathrm{NO}$ and $\mathrm{O}_{2}{ }^{\bullet-}$ production in the aorta $16 \mathrm{~h}$ after LPS administration, just when the vascular relaxation to acetylcholine was compromised (data not shown). Superoxide is an NO scavenger and rapidly reacts to form peroxynitrite $\left(\mathrm{ONOO}^{-}\right)$(31). eNOS uncoupling, whereby eNOS generates $\mathrm{O}_{2}{ }^{--}$rather than $\mathrm{NO}$, is an important mechanism underlying endothelial dysfunction (4). Endothelial dysfunction in sepsis is associated with reduced $\mathrm{NO}$ bioactivity and increased $\mathrm{O}_{2}{ }^{--}$production (4). Various studies have also shown that NOS may suffer oxidation during situations of intense oxidative stress, and this leads NOS to produce superoxide instead of NO $(28,29,32)$. Another explanation for this uncoupling is the oxidation of tetrahydrobiopterin, a critical cofactor for the NO synthases. When tetrahydrobiopterin is absent these enzymes become "uncoupled" $(28,33)$. The production of reactive oxygen species (ROS) in blood vessels occurs from two main sources. An NADPH oxidase, similar to the neutrophil oxidase, is present in endothelial and vascular smooth muscle cells and seems to be a source of ROS (13). In addition, the endothelial and neuronal NOS (eNOS and nNOS, respectively), both cytochrome $\mathrm{p} 450$ reductase-like

\section{References}

1. Angus DC, Linde-Zwirble WT, Lidicker J, Clermont G, Carcillo J, Pinsky MR. Epidemiology of severe sepsis in the United States: analysis of incidence, outcome, and associated costs of care. Crit Care Med 2001; 29: 1303-1310.

2. Bone RC. Sepsis, the sepsis syndrome, multi-organ failure: enzymes (14), can produce large amounts of ROS when deprived of their critical cofactor tetrahydrobiopterin or their substrate L-arginine (15-22).

Stimulation of astrocytic $\mathrm{P} 2 \mathrm{X} 7$ receptors, as well as other $\mathrm{P} 2$ receptors, has been shown to induce Akt activation (34). Extracellular ATP acting in part through Gi proteins increased PI3K activity in a time-dependent manner and a transient phosphorylation of Akt was produced (35). Western blotting measurements showed that $p$-Akt and p-eNOS were induced by ATP (Figure 7). The increase in the aorta content of $p$-eNOS occurred in both control and LPS animals. Although septic aortic rings showed a reduced amount of eNOS, ATP addition was effective in increasing the amount of p-eNOS. The eNOS enzyme has been shown to present higher activity when phosphorylated $(36,37)$. In the present experiments, ATP increased p-eNOS while simultaneously reducing superoxide production. The superoxide production through NOS activity was confirmed in the experiments using L-NAME, an NOS inhibitor. Literature data regarding different cell lines have shown that Akt directly phosphorylates eNOS (4). In order to check this pathway, in our study we showed that $p$-Akt was increased within a very short time after ATP stimulation. Akt may participate in the pathway inducing eNOS phosphorylation by ATP in LPS animals. A limitation of our study is that we did not check the effect of an Akt inhibitor on superoxide production and p-eNOS amount in order to confirm this pathway as determinant of the effects.

Normal vascular reactivity is a crucial factor in maintaining adequate blood perfusion. Septic vessels present severe functional impairment, which is associated with end-organ damage (38). ATP is an endogenous substance eliciting endothelium-dependent vascular relaxation. Even in the presence of endothelial dysfunction ATP produces effective vascular relaxation. Through the property shown in the present study of reducing superoxide production and increasing or maintaining NO release in conditions of endothelial damage, ATP is able to sustain better vascular reactivity. These findings suggest a novel role for ATP in the endothelium under oxidative stress, i.e., the induction of eNOS phosphorylation that "recouples" NOS activity with a consequent reduction in superoxide production and with the occurrence of appropriate vasorelaxation. The development of compounds and drugs with an action based on purinergic activation would be highly desirable for the treatment of septic endothelial dysfunction. 
et al. Stoichiometric relationships between endothelial tetrahydrobiopterin, endothelial NO synthase (eNOS) activity, and eNOS coupling in vivo: insights from transgenic mice with endothelial-targeted GTP cyclohydrolase 1 and eNOS overexpression. Circ Res 2005; 97: 864-871.

5. Brandes RP, Koddenberg G, Gwinner W, Kim D, Kruse HJ, Busse $\mathrm{R}$, et al. Role of increased production of superoxide anions by $\mathrm{NAD}(\mathrm{P}) \mathrm{H}$ oxidase and xanthine oxidase in prolonged endotoxemia. Hypertension 1999; 33: 1243-1249.

6. Javesghani D, Hussain SN, Scheidel J, Quinn MT, Magder SA. Superoxide production in the vasculature of lipopolysaccharide-treated rats and pigs. Shock 2003; 19: 486-493.

7. Azevedo LC, Janiszewski M, Soriano FG, Laurindo FR. Redox mechanisms of vascular cell dysfunction in sepsis. Endocr Metab Immune Disord Drug Targets 2006; 6: 159164.

8. Dahlback B. Physiological anticoagulation. Resistance to activated protein $\mathrm{C}$ and venous thromboembolism. J Clin Invest 1994; 94: 923-927.

9. Zimmermann T, Gardemann A, Machnik G, Dargel R, Jungermann K. Metabolic and hemodynamic responses of bivascularly perfused rat liver to nerve stimulation, noradrenaline, acetylcholine and glucagon in thioacetamide-induced micronodular cirrhosis. Hepatology 1992; 15: 464-470.

10. Persechini PM, Bisaggio RC, Alves-Neto JL, Coutinho-Silva R. Extracellular ATP in the lymphohematopoietic system: P2Z purinoceptors and membrane permeabilization. Braz $J$ Med Biol Res 1998; 31: 25-34.

11. Nihei OK, Savino W, Alves LA. Procedures to characterize and study P2Z/P2X7 purinoceptor: flow cytometry as a promising practical, reliable tool. Mem Inst Oswaldo Cruz 2000; 95: 415-428.

12. Sartorello R, Garcia CR. Activation of a P2Y4-like purinoceptor triggers an increase in cytosolic $\left[\mathrm{Ca}^{2+}\right]$ in the red blood cells of the lizard Ameiva ameiva (Squamata, Teiidae). Braz J Med Biol Res 2005; 38: 5-10.

13. Burnstock $G$. Purinergic signalling: past, present and future. Braz J Med Biol Res 2009; 42: 3-8.

14. Brake A, Schumacher M, Julius D. ATP receptors in sickness, pain and death. Chem Biol 1996; 3: 229-232.

15. Galkin A, Higgs A, Moncada S. Nitric oxide and hypoxia. Essays Biochem 2007; 43: 29-42.

16. Moncada S, Bolanos JP. Nitric oxide, cell bioenergetics and neurodegeneration. J Neurochem 2006; 97: 1676-1689.

17. Soriano FG, Virag L, Szabo C. Diabetic endothelial dysfunction: role of reactive oxygen and nitrogen species production and poly(ADP-ribose) polymerase activation. $J \mathrm{Mol}$ Med 2001; 79: 437-448.

18. Mortensen SP, Gonzalez-Alonso J, Bune LT, Saltin B, Pilegaard $\mathrm{H}$, Hellsten $\mathrm{Y}$. ATP-induced vasodilation and purinergic receptors in the human leg: roles of nitric oxide, prostaglandins, and adenosine. Am J Physiol Regul Integr Comp Physiol 2009; 296: R1140-R1148.

19. Gozal E, Forman HJ, Torres M. ADP stimulates the respiratory burst without activation of ERK and AKT in rat alveolar macrophages. Free Radic Biol Med 2001; 31: 679-687.

20. Suh BC, Kim JS, Namgung U, Ha H, Kim KT. P2X7 nucleotide receptor mediation of membrane pore formation and superoxide generation in human promyelocytes and neutrophils. J Immunol 2001; 166: 6754-6763.

21. Hasko G, Szabo C. Regulation of cytokine and chemokine production by transmitters and co-transmitters of the au- tonomic nervous system. Biochem Pharmacol 1998; 56: 1079-1087.

22. Sprague RS, Ellsworth ML, Stephenson AH, Lonigro AJ. ATP: the red blood cell link to NO and local control of the pulmonary circulation. Am J Physiol 1996; 271: H2717H2722.

23. Garcia Soriano F, Liaudet L, Marton A, Hasko G, Batista Lorigados C, Deitch EA, et al. Inosine improves gut permeability and vascular reactivity in endotoxic shock. Crit Care Med 2001; 29: 703-708.

24. Traut TW. Physiological concentrations of purines and pyrimidines. Mol Cell Biochem 1994; 140: 1-22.

25. Holmsen H, Weiss HJ. Secretable storage pools in platelets. Annu Rev Med 1979; 30: 119-134.

26. Ellsworth ML. The red blood cell as an oxygen sensor: what is the evidence? Acta Physiol Scand 2000; 168: 551-559.

27. Hink $\mathrm{U}$, Li H, Mollnau $\mathrm{H}$, Oelze M, Matheis E, Hartmann $M$, et al. Mechanisms underlying endothelial dysfunction in diabetes mellitus. Circ Res 2001; 88: E14-E22.

28. Landmesser U, Dikalov S, Price SR, McCann L, Fukai T, Holland SM, et al. Oxidation of tetrahydrobiopterin leads to uncoupling of endothelial cell nitric oxide synthase in hypertension. J Clin Invest 2003; 111: 1201-1209.

29. Zou MH, Shi C, Cohen RA. Oxidation of the zinc-thiolate complex and uncoupling of endothelial nitric oxide synthase by peroxynitrite. J Clin Invest 2002; 109: 817-826.

30. Mata-Greenwood E, Jenkins C, Farrow KN, Konduri GG, Russell JA, Lakshminrusimha $S$, et al. eNOS function is developmentally regulated: uncoupling of eNOS occurs postnatally. Am J Physiol Lung Cell Mol Physiol 2006; 290: L232-L241.

31. Cuzzocrea S, Mazzon E, Dugo L, Di Paola R, Caputi AP, Salvemini D. Superoxide: a key player in hypertension. FASEB J 2004; 18: 94-101.

32. Fukai T, Siegfried MR, Ushio-Fukai M, Cheng Y, Kojda G, Harrison DG. Regulation of the vascular extracellular superoxide dismutase by nitric oxide and exercise training. J Clin Invest 2000; 105: 1631-1639.

33. Xia Y, Tsai AL, Berka V, Zweier JL. Superoxide generation from endothelial nitric-oxide synthase. $\mathrm{A} \mathrm{Ca}^{2+} /$ calmodulindependent and tetrahydrobiopterin regulatory process. J Biol Chem 1998; 273: 25804-25808.

34. Jacques-Silva MC, Rodnight R, Lenz G, Liao Z, Kong Q, Tran M, et al. P2X7 receptors stimulate AKT phosphorylation in astrocytes. Br J Pharmacol 2004; 141: 1106-1117.

35. Gerasimovskaya EV, Tucker DA, Weiser-Evans M, Wenzlau JM, Klemm DJ, Banks M, et al. Extracellular ATP-induced proliferation of adventitial fibroblasts requires phosphoinositide 3-kinase, Akt, mammalian target of rapamycin, and p70 S6 kinase signaling pathways. J Biol Chem 2005; 280: 1838-1848.

36. Chen CA, Druhan LJ, Varadharaj S, Chen YR, Zweier JL. Phosphorylation of endothelial nitric-oxide synthase regulates superoxide generation from the enzyme. J Biol Chem 2008; 283: 27038-27047.

37. Zhang Q, Malik P, Pandey D, Gupta S, Jagnandan D, Belin de CE, et al. Paradoxical activation of endothelial nitric oxide synthase by NADPH oxidase. Arterioscler Thromb Vasc Biol 2008; 28: 1627-1633.

38. Scalia R, Pearlman S, Campbell B, Lefer AM. Time course of endothelial dysfunction and neutrophil adherence and infiltration during murine traumatic shock. Shock 1996; 6: 177-182. 